\title{
Differential interactions of halophilic and non-halophilic proteases with nanoparticles
}

\author{
Rajeshwari Sinha and Sunil K Khare
}

\begin{abstract}
Background: Increase in the industrial use of nanomaterials and nanoparticles (NPs) make their release into the environment inevitable. This may lead to environmental contamination and exposure of the biological/ microbial diversity. Nanoparticles have been reported to impregnate the cells and interact with cellular biomolecules especially proteins and DNA, leading to nanotoxicity in many cases. The present work targets to study nanoparticle-protein interactions in-vitro, especially to assess their effects on extracellularly secreted enzymes. The primary extracellular enzymes viz. hydrolases and proteases could be the first to come in contact with environmentally released nanoparticles.

Results: Two halophilic proteases from Geomicrobium sp. EMB2 and Bacillus sp. EMB9 and one non-halophilic protease, subtilisin from Bacillus licheniformis have been investigated for their interaction with silver and zinc oxide nanoparticles as model systems. The activities of Geomicrobium sp. and Bacillus sp. protease were unaffected while that of non-halophilic subtilisin was lost by $70 \%$ and $30 \%$ in presence of $\mathrm{Ag}$ and $\mathrm{ZnO}$ nanoparticles respectively. The secondary and tertiary structure of halophilic proteases was unchanged on exposure to $\mathrm{ZnO}$ and $\mathrm{Ag}$ nanoparticles. Non-halophilic protease showed significant loss in a-helical structure with changes in the microenvironment of the protein as observed by CD and fluorescence spectroscopy. The greater stability and structural integrity may be attributed to higher negative charges on the surfaces of halophilic proteins.

Conclusions: Halophilic extracellular proteases were more stable and did not lose proteolytic activity. Their secondary structure remained unaffected by interaction with $\mathrm{ZnO}$ and $\mathrm{Ag}$ nanoparticles. Alterations in structure and loss of activity in non-halophilic protease have been quite prevalent on exposure to nanoparticles. The extracellular halophilic nanostable enzymes thus offer a promising robust system to counter nanotoxicity. A precise understanding of nanoparticle interaction with extracellular enzymes will pave the way for designing of novel enzymes and creating appropriate system to protect microbial diversity against nanoparticle disposal.
\end{abstract}

Keywords: Halophiles, Protease, Nanoparticles, Bacillus sp

\section{Background}

The toxic effects of nanoparticles are being increasingly evidenced. Studies pertaining to the effects of nanoparticles on animals and cell culture have clearly revealed the loss of cell viability, tissue damage and inflammatory reactions [1]. Carbon nanomaterials, metals, metal oxide viz. gold, silver, zinc oxide, titanium dioxide nanoparticles and quantum dots have been shown to work as biocidal agents against broad spectrum of bacteria such as E. coli, S. aureus, B. subtilis and P. aeruginosa etc. [2]. Nanoparticle induced cytotoxicity in mammalian

\footnotetext{
* Correspondence: skhare@rocketmail.com

Enzyme and Microbial Biochemistry Laboratory, Department of Chemistry, Indian Institute of Technology, Delhi, Hauz Khas, New Delhi 110016, India
}

fibroblast cells, macrophages, human hepatoma cells has been similarly evidenced [3]. These studies have further demonstrated that nanoparticles are quite reactive and interact with cellular biomolecules. Proteins undergo structural changes when interacting with ligands. Nanoparticles serve as very reactive ligands for protein due to their large surface to volume ratio and high biocompatibility. The present work targets to study nanoparticleprotein interactions in-vitro, especially to assess their effects on extracellularly secreted enzymes. The primary extracellular enzymes viz. hydrolases and proteases could be the first to come in contact with environmentally released nanoparticles.
(C) Chemistry Central

(C) 2014 Sinha and Khare; licensee Chemistry Central Ltd. This is an Open Access article distributed under the terms of the Creative Commons Attribution License (http://creativecommons.org/licenses/by/2.0), which permits unrestricted use,

distribution, and reproduction in any medium, provided the original work is properly credited. The Creative Commons Public Domain Dedication waiver (http://creativecommons.org/publicdomain/zero/1.0/) applies to the data made available in this article, unless otherwise stated. 
An important aspect in understanding the mechanism of nanoparticle's impending behavior towards biological systems is to elucidate their precise interaction with proteins. The dispersion of nanoparticles in a biological milieu results in their surfaces being immediately enveloped by a complex layer of proteins forming a "protein corona" [4]. Adsorption of proteins on the surface strongly depends on the nature of the protein, the surface chemistry and physicochemical properties. Subsequent to adsorption, electrostatic, hydrogen bonding and hydrophobic interactions provide further binding between proteins and nanoparticles. This leads to conformational changes in proteins, transformation into molten globule states, coadsorption or release of other ions and gain in entropy [5]. Since the structure and function of proteins are explicitly related, a fundamental understanding of the conformational changes of adsorbed proteins would be critical in evaluating nanoparticles induced cellular response. As the interactions depend on the protein size, shape, charge, hydrophobicity and surface geometry, it would be interesting to investigate different types of proteins for better understanding. Very limited information is available on differential interactions of nanoparticles with varying kinds of proteins.

We have previously reported that halophilic cells interact differently with nanoparticle and offer significant resistance to the nanotoxicity as compared to the nonhalophilic cells [6]. Halophiles are the class of organisms which inhabit saline/hypersaline environments. Their proteins have highly charged surfaces for enabling them to retain structural and functional integrity under high salt concentration [7]. They also retain native conformation against most of the denaturants viz. urea, guanidium chloride, organic solvents etc. [8,9]. It would be worthwhile to compare whether non-halophilic and halophilic proteins respond differently towards nanoparticles. Such study would add to the current understanding of nanoparticle-protein interactions.

Nanoparticles are highly reactive materials with altered properties because of reduction to nanosize. Conjugation of NPs to proteins has found beneficial applications in imaging, catalysis, drug delivery and understanding a local structure in protein folding [10-13]. Zinc oxide $(\mathrm{ZnO})$ and silver $(\mathrm{Ag})$ nanoparticles are two most widely used nanoparticles in recent years. Applications of $\mathrm{Ag}$ nanoparticles is quite established as antibacterial agents in wound dressings, coatings of biomedical devices, deodorants, washing machines, textiles [14] and $\mathrm{ZnO}$ nanoparticles in ceramics, sunscreens, as UV absorbers in textiles as well as in bioimaging are well documented [15]. In the present work, the effects of $\mathrm{Ag}$ and $\mathrm{ZnO}$ nanoparticles have been studied on their biological activity and conformational transitions of two halophilic proteases from Geomicrobium sp. EMB2 and Bacillus sp.
EMB9. These are compared with commercial nonhalophilic Bacillus sp. protease. The study will have implications in assessing the impact of release of nanoparticles on biodiversity.

\section{Results and discussion}

Effect of nanoparticles on protease activity

The effects of nanoparticles on the enzyme activity of halophilic and non-halophilic proteases are shown in Figure 1. The exposure of $\mathrm{Ag}$ and $\mathrm{ZnO}$ nanoparticles $(1 \mathrm{mM})$ caused a significant decrease in the activity of non-halophilic B. licheniformis protease. Ag nanoparticles were more diminutive leading to a $70 \%$ decrease in activity as compared to $30 \%$ by $\mathrm{ZnO}$ nanoparticles. On the contrary the halophilic proteases were more stable towards both the nanoparticles at this concentration (1 mM). Halophilic Bacillus sp. protease exhibited slight enhancement in activity, whereas there was a marginal loss in case of Geomicrobium sp. protease.

Proteins bind onto the nanoparticle surfaces by electrostatic, hydrophobic as well as hydrogen bonding interactions [5]. Non-halophilic subtilisin Carlsberg from B. licheniformis contains 274 amino acid residues with higher proportion of aromatic and hydrophobic residues [16]. The frequency of acidic amino acid residues in subtilisin Carlsberg is only about $5.1 \%$ of the total number of residues [17]. On the contrary, the halophilic proteases possess greater number of acidic amino acid residues on their surface as an adaptive feature to withstand salinity [7]. Acidic residues constituted almost $12.5 \%$ of the total amino acid composition in Geomicrobium sp. EMB2 protease [18]. Very recently, genomic and proteomic studies have also established the significance of negatively charged amino acid residues on the halophilic protein surface [18-20]. It may therefore be inferred that

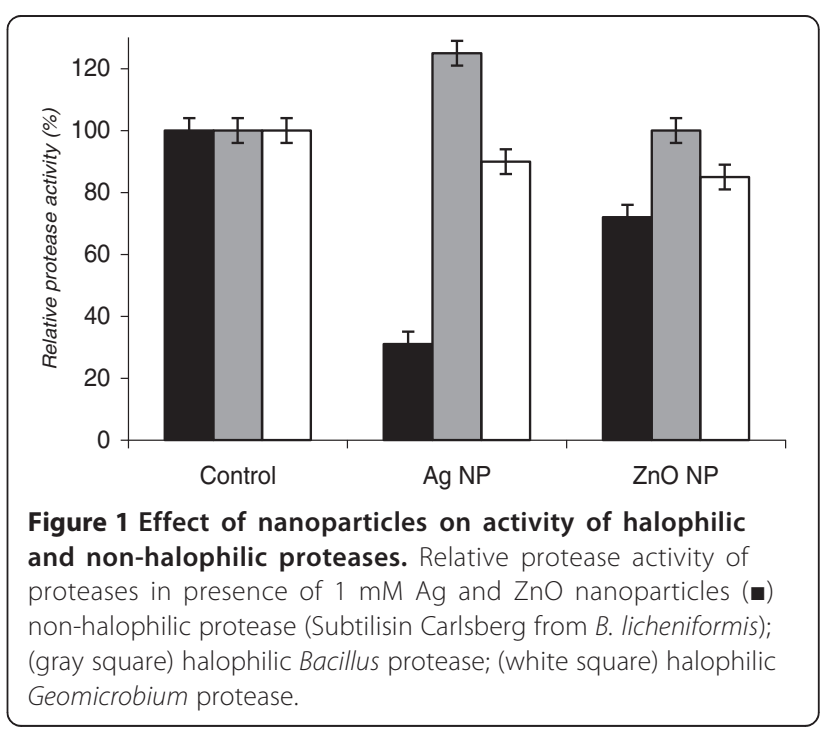


nanoparticles are adsorbed differentially in halophilic and non-halophilic proteases due to the influence of charge. Stronger binding of cationic gold nanoparticles to $\beta$-lactoglobulin (BLG) isomer BLGA over BLGB was attributed to the presence of additional aspartate residues [21]. The higher affinity of the nanoparticle for the protein may arise due to strong electrostatic interaction between positive charge density of the nanoparticle with the negatively charged domain on the protein. Adherence of halophilic proteases onto nanoparticle surface may have influenced the conformation into functionally favourable form, and a less active conformation in case of non-halophilic subtilisin.

\section{Conformational changes in nanoparticle treated proteases}

In order to probe the changes in conformation in above cases, circular dichroism spectra were recorded subsequent to nanoparticle-protein interactions. From the secondary structure analysis of the $\mathrm{CD}$ spectra, it was quite evident that interaction between proteases and nanoparticles led to conformational perturbations

The $\alpha$-helical content of non-halophilic proteases was significantly lost in presence of $\mathrm{Ag}$ and $\mathrm{ZnO}$ nanoparticles (Figure 2). On the contrary, the helical and sheet content of halophilic Bacillus sp. and Geomicrobium sp. proteases remained mostly unchanged (Figures $3 a$ and $b$ ). The secondary structure remained prominently $\alpha$-helical. There was, however, a slight decrease in this negative ellipticity on exposure to nanoparticles. The hydrogen bonding and ionic interactions predominantly existing in $\alpha$-helix may have been disturbed upon nanoparticle binding. Similar structural perturbations in lysozyme and the periplasmic domain of Vibrio cholerae ToxR protein upon exposure to $\mathrm{ZnO}$ nanoparticles have been previously reported [22,23].

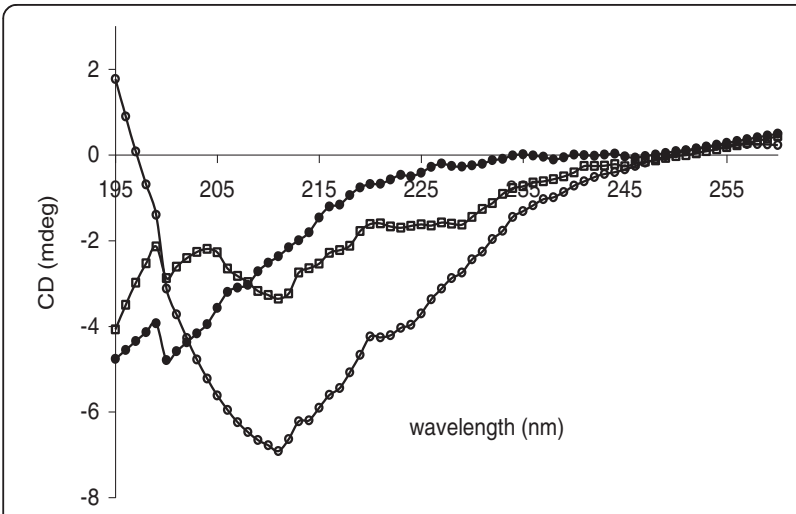

Figure 2 Effect of nanoparticles on secondary structure of non-halophilic $B$. licheniformis proteases. Far-UV CD spectra of non-halophilic protease in absence and presence of nanoparticles.

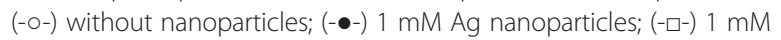
ZnO nanoparticles.
The secondary structural perturbations in Bacillus sp. EMB9 protease was also confirmed by FTIR spectroscopy. Results obtained from FTIR, although preliminary, revealed prominent peaks and supported the observations evidenced in case of CD spectra (Figures $4(\mathrm{a}-\mathrm{c})$ ). The overall IR spectra for control as well as Ag and $\mathrm{ZnO}$ nanoparticles treated EMB9 protease showed that the basic structure of the protease was retained. For the free EMB9 protease, the Amide A band due to N-H stretching vibrations was obtained at $3450 \mathrm{~cm}^{-1}$. The position of the Amide A band however shifted towards lower wavenumbers upon interaction with nanoparticles. Relevant conclusions on the conformational changes in protein can be drawn from the amide I and II bands which appear in the $1500-1700 \mathrm{~cm}^{-1}$ region. The amide I band has significant correlation with the protein secondary structure and appears in the $1600-1700 \mathrm{~cm}^{-1}$ region. As compared to the amide I band for the control $\left(\sim 1642 \mathrm{~cm}^{-1}\right)$, those for nanoparticle treated proteases showed changes in intensity and small shifts in peak positions. Absorption in the amide I region is based on $\mathrm{C}=\mathrm{O}$ stretching vibrations and is definitely suggestive of interactions between protease and nanoparticles leading to conformational alterations. It is possible that the size and characteristics of nanoparticles along with the charge distribution pattern on the protein play vital roles in determining how the nanoparticles affect the structure of the protein.

As regard to the tertiary structure, nanoparticles induced the quenching of the intrinsic tryptophan fluorescence for both halophilic and non-halophilic proteases. The fluorescence spectra for Bacillus sp. EM9 protease with varying $\mathrm{ZnO}$ nanoparticle concentration is shown in Figure 5. Increased fluorescence quenching with increasing nanoparticle concentrations indicate changes in microenvironment of the proteases due to nanoparticleprotein interactions. Quenching of the intrinsic fluorescence by nanoparticles has also been previously reported in case of Bacillus amyloliquefaciens $\alpha$-amylase by tin oxide nanoparticles [24]. The decreasing fluorescence intensity with increasing nanoparticle concentration may be attributed to the transfer of energy from the protein to the nanoparticles.

The differential effect of nanoparticles on halophilic and non-halophilic proteases, with respect to alterations in secondary structures and changes in microenvironment in tertiary structure, correlated well with the activity data. The loss of helix in subtilisin on binding to nanoparticles explains the loss of proteolytic activity, whereas insignificant change in helix and sheets of halophilic proteases are quite in agreement with their retaining proteolytic activity after nanoparticle interactions. The results indicate that nanoparticles tend to differ in their interaction with nonhalophilic and halophilic proteases. 


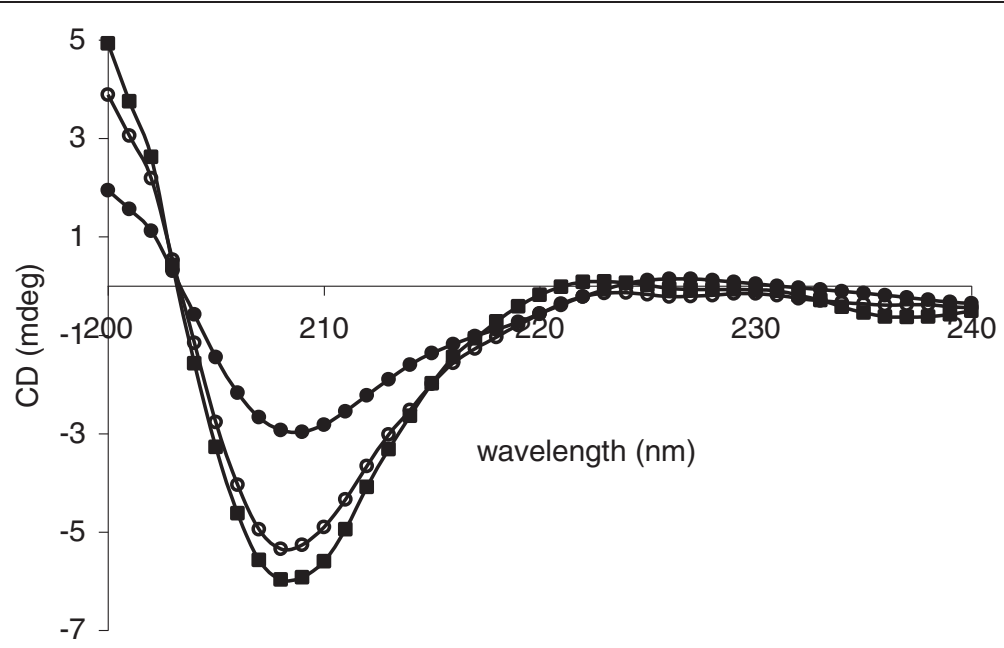

(a)

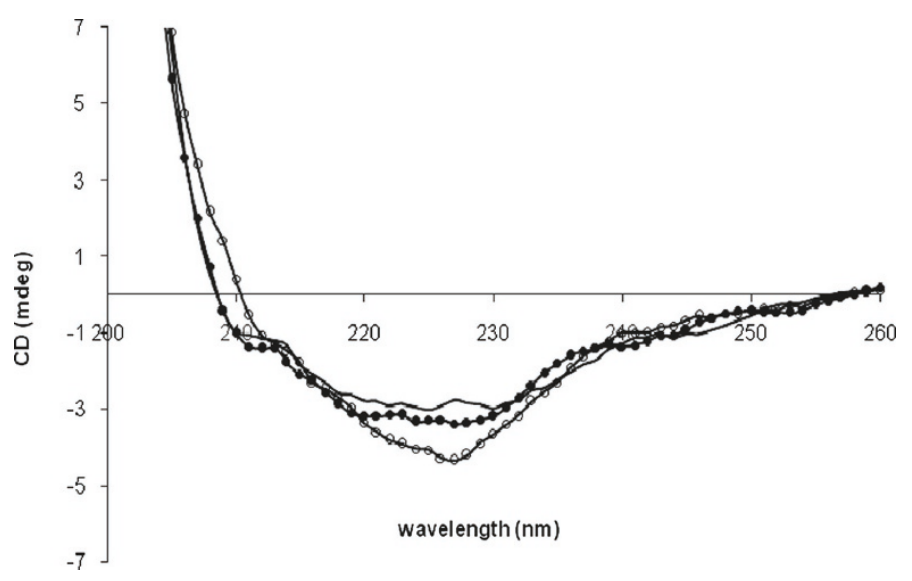

(b)

Figure 3 Effect of nanoparticles on secondary structure of halophilic proteases. (a) Far- UV CD spectra of halophilic Bacillus sp. protease in absence and presence of nanoparticles. (-o-) without nanoparticles; (--) 1 mM Ag nanoparticles; (-•-) 1 mM ZnO nanoparticles (b) Far UV CD spectra of halophilic Geomicrobium sp. protease in absence and presence of nanoparticles. (-o-) without nanoparticles; (- $\bullet 1 \mathrm{mM}$ Ag nanoparticle; (一) $1 \mathrm{mM}$ ZnO nanoparticles.

Previous investigations on interaction of nanoparticles with different proteins have led to following understanding so far:

(i) A possible two step nanoparticle-protein binding model: Studies on lysozyme interaction with $\mathrm{TiO}_{2}$ nanoparticles suggested that lysozyme is initially adsorbed onto nanoparticle surface by electrostatic interaction. Subsequently, hydrogen bond formation takes place between between polar side groups of enzyme and $\mathrm{TiO}_{2}$ nanoparticle. This second interaction leads to disruption of the native enzyme structure [25]. Similar factors may have been responsible for the loss of structure and activity of non-halophilic B. licheniformis protease by $\mathrm{Ag}$ and $\mathrm{ZnO}$ nanoparticles. (ii) Protein adsorption on the nanoparticle surface is governed by various factors viz. protein conformation, surface properties and surface energy [5]. It is likely that the proteins may have adsorbed strongly on to the nanoparticle surface through multipoint attachment [26]. Taking this into account, it appears that structural integrity of halophilic proteases may have been enhanced by electrostatic interaction between nanoparticle and charged surface of halophilic proteases. Higher amount of negatively charged residues on halophilic protein surface may have triggered a multipoint adherence of the enzyme on nanoparticle surface thereby imparting molecular rigidity. The strong attachment and restricted conformational flexibility 


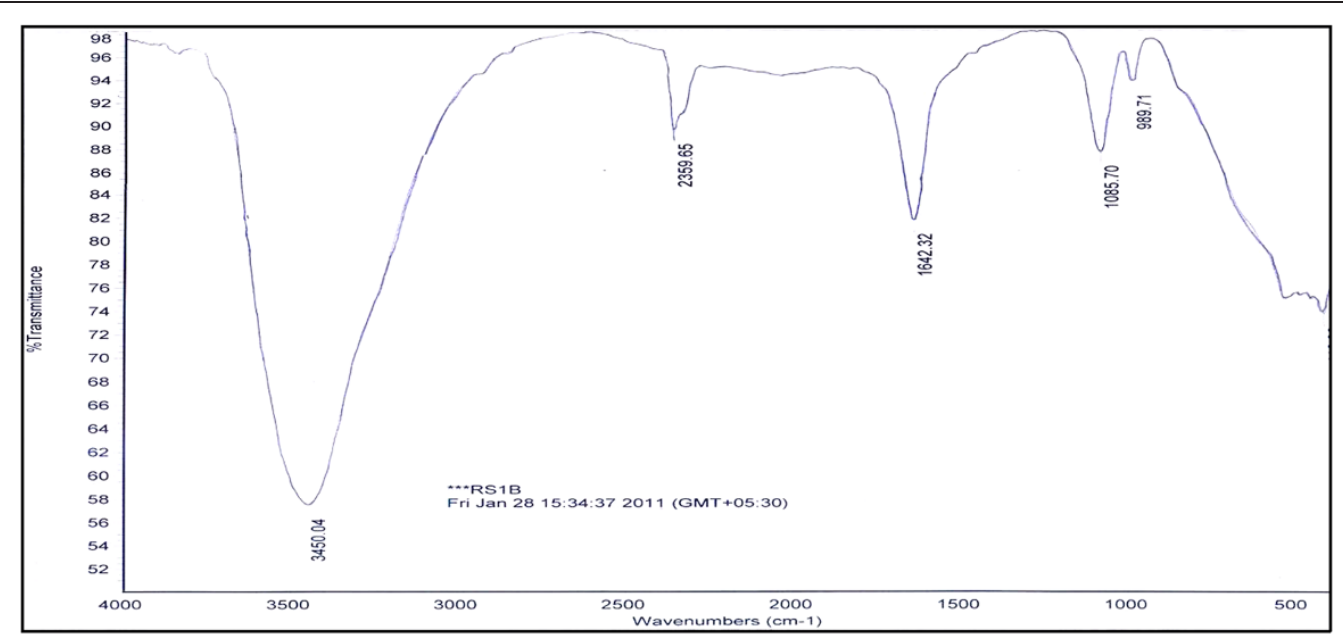

(a)

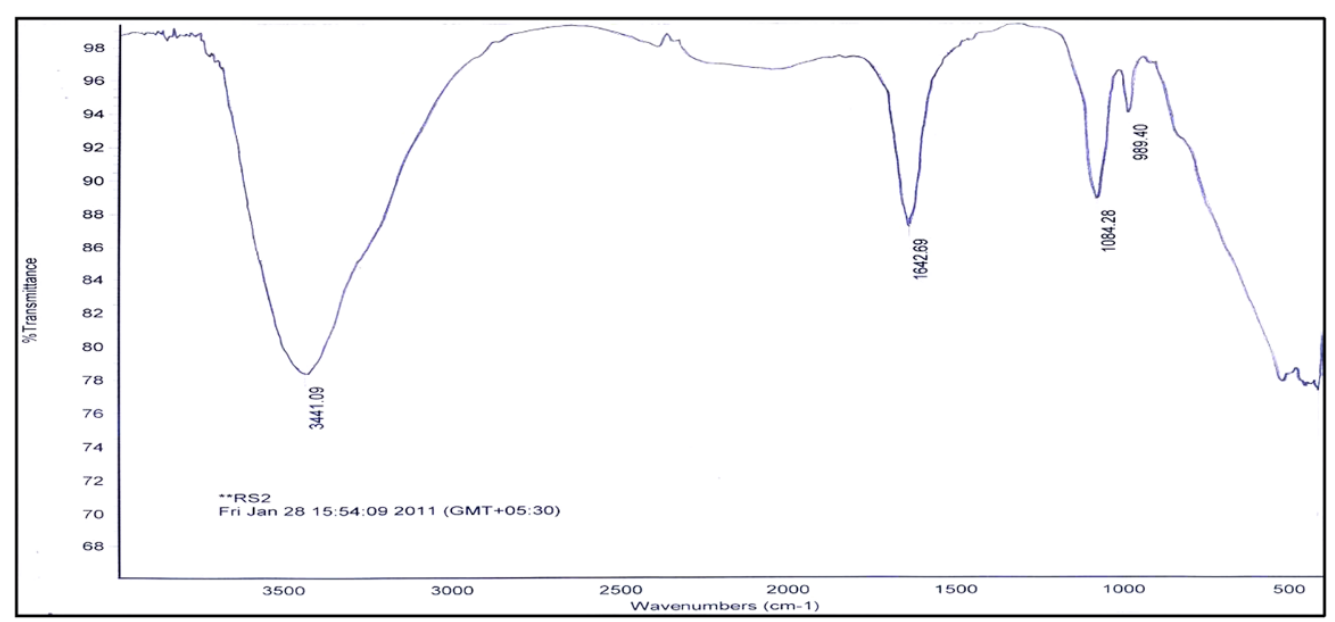

(b)

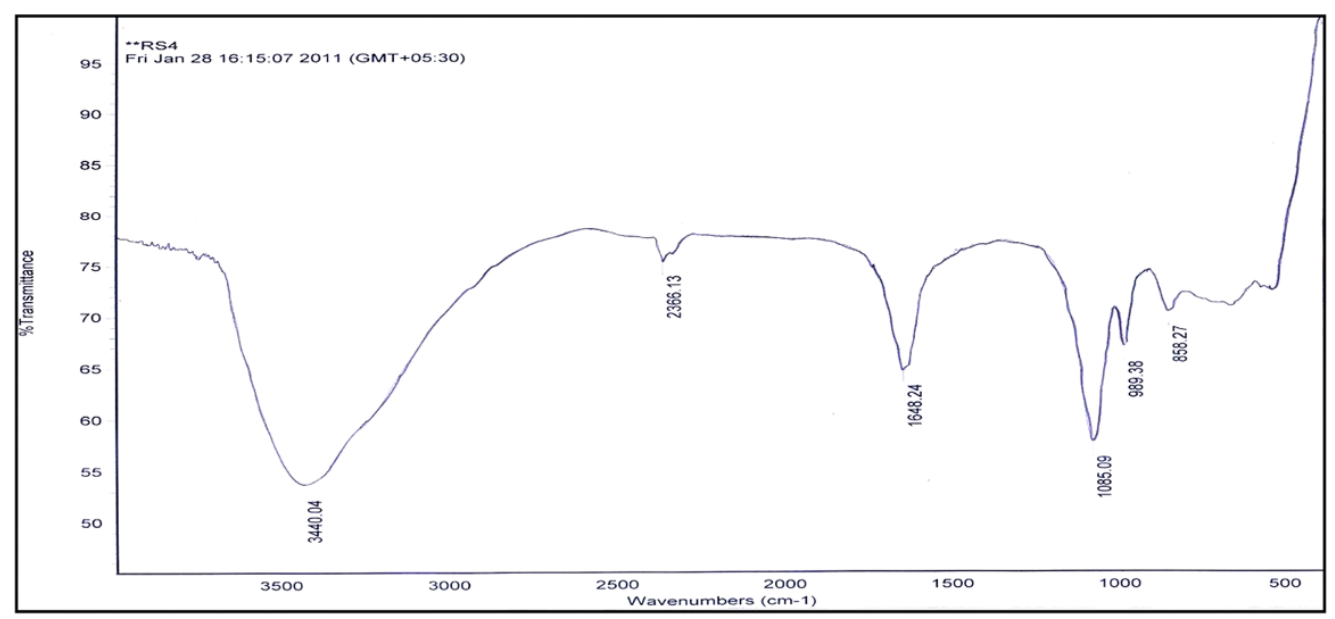

(c)

Figure 4 FTIR spectra of Bacillus sp. EMB9 protease before and after interaction with nanoparticles. (a) control; (b) Ag nanoparticle treated; (c) ZnO nanoparticle treated. 


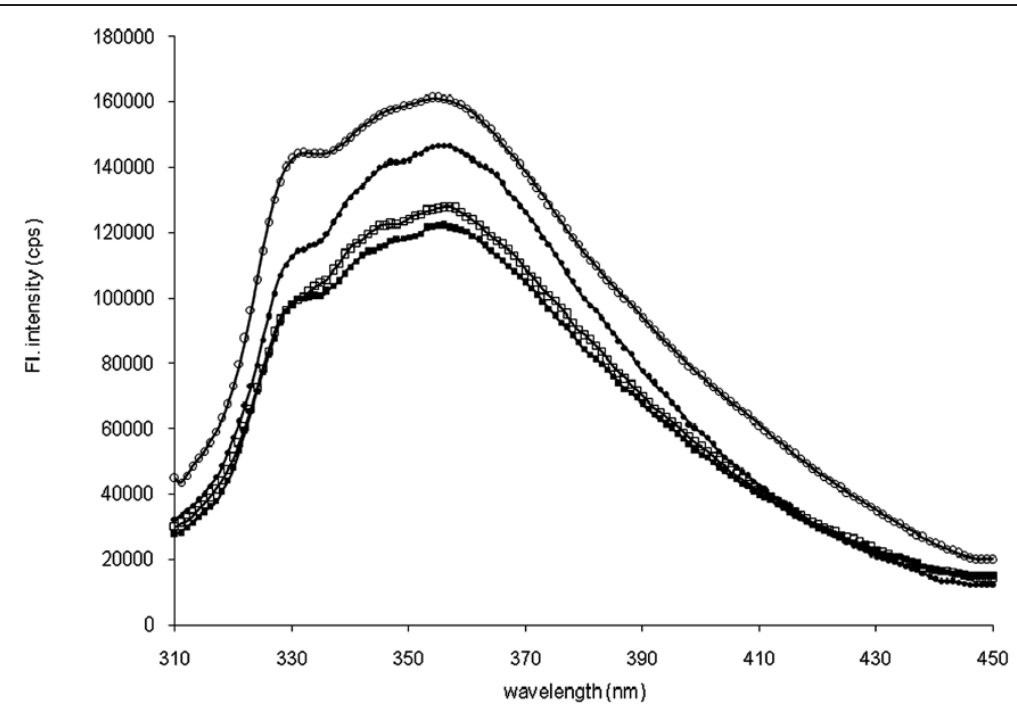

Figure 5 Effect of nanoparticles on tertiary structure of halophilic Bacillus sp. EMB9 protease. Fluorescence spectra (excitation wavelength

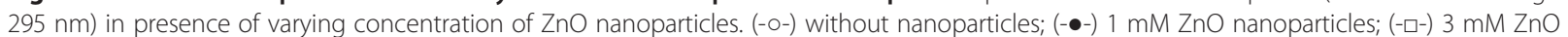
nanoparticles; (-m-) $5 \mathrm{mM}$ ZnO nanoparticles.

might be responsible in preventing unfolding or denaturation of the secondary/tertiary structure of the halophilic proteins. Consequently, the EMB9 and EMB2 proteases were catalytically active and retained structural integrity in the presence of nanoparticle.

\section{Experimental}

\section{Halophilic and non-halophilic proteases}

The purified proteases from the halophilic lab isolates Bacillus sp. EMB9, and Geomicrobium sp. EMB2, were used in the present study The strains were grown for protease production and the proteases were purified by $\mathrm{CM}$ cellulose chromatography in case of Bacillus sp. EMB9 protease [27] and by hydrophobic interaction chromatography in case of Geomicrobium sp. EMB2 following the previously developed protocols by us [28]. The non-halophilic Subtilisin Carlsberg protease from B. licheniformis was procured from Sigma Aldrich Corp. USA (Catalogue no. P5380).

Protease activity was assayed towards casein as substrate by following the method of Shimogaki et al. [29]. Briefly, $0.5 \mathrm{ml}$ of the enzyme was added to $3.0 \mathrm{ml}$ casein $(0.6 \%$, w/v in $50 \mathrm{mM}$ Tris- $\mathrm{HCl}$ buffer, $\mathrm{pH} 8.0$ for subtilisin Carlsberg, pH 9.0 for Bacillus sp. EMB9 and in $50 \mathrm{mM}$ Borax buffer pH 10.0 for, Geomicrobium sp. protease). For halophilic proteases, $1 \%(\mathrm{w} / \mathrm{v}) \mathrm{NaCl}$ was also added into the assay buffers $(50 \mathrm{mM}$ Tris- $\mathrm{HCl}$ buffer, $\mathrm{pH} 8.0$ and $50 \mathrm{mM}$ Borax buffer $\mathrm{pH} 10.0$ ) since salt was essentially required for optimum activity of these enzymes. The mixture was incubated at $55^{\circ} \mathrm{C}$ for $20 \mathrm{~min}$ followed by stopping of the reaction by adding $3.2 \mathrm{ml}$ of TCA mixture $(0.1 \mathrm{M}$ trichloroacetic acid, $0.2 \mathrm{M}$ sodium acetate and $0.3 \mathrm{M}$ acetic acid). The mixture was further kept at room temperature for $30 \mathrm{~min}$. The precipitates were removed by filtration through Whatman-1 filter paper and the absorbance of the filtrate was measured at $280 \mathrm{~nm}$ (UVmini 1240 spectrophotometer, Shimadzu, Japan) against corresponding enzyme blanks processed similarly. One unit of activity is defined as the amount of enzyme required to liberate $1 \mu \mathrm{g}$ of tyrosine per min under assay conditions. The protein concentration was determined by the dye binding assay [30] using bovine serum albumin as standard.

\section{Circular dichroism}

Far UV-CD spectra of the protease was recorded between 195 and $260 \mathrm{~nm}$ on a Chirascan Spectropolarimeter (Applied Photophysics, Leatherhead, Surrey, UK) at $20^{\circ} \mathrm{C}$ using $1 \mathrm{~mm}$ quartz cuvette. All measurements were performed in $5 \mathrm{mM}$ Tris Buffer, $(\mathrm{pH}$ 8.0, 9.0 and $\mathrm{pH} 10.0$ for subtilisin protease, Bacillus sp. and Geomicrobium sp. protease respectively), at $0.5 \mathrm{mg} / \mathrm{ml}$ protein concentration. The contribution of respective buffers was subtracted from experimental spectra with further smoothing using mild smoothing function. Average of three independent scans was taken. The secondary structural content of the proteases from the CD spectra were analysed by web server K2D2, EMBL (Heidelberg, Germany) [31].

\section{Fluorescence spectroscopy}

Fluorescence spectra were acquired on spectrofluorometer (model Fluoromax-4, Horiba-Jobin Yvon Inc, New Jersey, USA) at $25^{\circ} \mathrm{C}$ using $1 \mathrm{~cm}^{2}$ path length quartz cuvettes. The excitation wavelength was kept at $295 \mathrm{~nm}$ and 
emission spectra were recorded between 305 and $400 \mathrm{~nm}$. The protein concentration was kept at $50 \mu \mathrm{g} / \mathrm{ml}$ and baselines were corrected with the corresponding buffers. The data was recorded in triplicate and averaged. The analysis was performed by Origin 8.0 software (Masachusetts, USA).

\section{Fourier transform infrared (FTIR) spectroscopy}

The conformation of the proteases under study was also monitored using FTIR (FTIR Spectrometer, Nicolet, Protege 460). The control and treated samples were lyophilized for removal of water. One mg of lyophilized samples was grinded and mixed homogeneously with $100 \mathrm{mg}$ of spectroscopy grade $\mathrm{KBr}$ and dried completely. This was then subjected to a $13 \mathrm{~mm}$ die to make a transparent and homogeneous pellet. The band assignments to protease were collected in the range of 4000-500 $\mathrm{cm}^{-1}$. The reported spectra were an average of three scans at $4 \mathrm{~cm}^{-1}$ resolution.

\section{Effect of nanoparticles on activity and structure of proteases}

Zinc oxide ( $\mathrm{ZnO})$ [Cat. no 544906] and silver nanopowder (Ag) [Cat. no. 576832] were purchased from Sigma Chemical Company, St. Louis, USA. The average size of $\mathrm{ZnO}$ and $\mathrm{Ag}$ nanoparticles as determined by TEM was 35 and $70 \mathrm{~nm}$ respectively. Stock suspensions of $\mathrm{ZnO}$ and Ag nanoparticles were prepared by suspending preweighed quantity in Milli-Q water $(10 \mathrm{mg} / \mathrm{ml})$. The suspension was ultrasonicated for $30 \mathrm{~min}$, prior to each experiment, so as to prevent aggregation. Suitably diluted nanoparticle solutions were added in $1 \mathrm{ml}$ of purified protease solutions $(0.5 \mathrm{mg} / \mathrm{ml})$. Final concentration of nanoparticles was studied in the range of 1-5 mM. The mixture was vortexed and incubated at $25^{\circ} \mathrm{C}$ for $2 \mathrm{~h}$. Since maximum inhibition was observed at $1 \mathrm{mM}$, at which the structural perturbations were also distinctly noticeable, further studies viz. protease activity, CD and fluorescence spectroscopy of the samples were recorded to monitor the effect at $1 \mathrm{mM}$ concentration only.

All the experiments were performed in triplicates and variation was within $\pm 5 \%$.

\section{Conclusion}

The present work reports for the first time the effects of nanoparticles on enzymatic activity and secondary/ tertiary structural transitions of halophilic proteases. Halophilic proteases exhibited increased tolerance towards nanoparticle induced denaturation and retained greater stability in comparison to non-halophilic counterparts. Non-halophilic protease was significantly susceptible to nanoparticles. Ability of halophilic enzymes to withstand rapid denaturation may be attributed to higher negative charges on the surfaces. The work sheds light on differential behavior of halophilic and non-halophilic proteins towards nanoparticles. It is likely to have an impact in the area of halophilic proteins wherein (i) a mechanistic understanding may be clarified (ii) tools may be developed for taking care of nanoparticle affluence or (iii) new proteins may be designed for application in nanotechnology.

\section{Competing interests}

The authors declare that there is no conflict of interest.

\section{Authors' contributions}

RS carried out the experimental work. RS and SKK drafted the manuscript. All authors read and approved the final manuscript.

\section{Acknowledgements}

The financial support provided by the Department of Biotechnology (Government of India) is gratefully acknowledged. Author Rajeshwari Sinha is grateful to the Council of Scientific and Industrial Research (CSIR), Government of India, for providing the Research Fellowship.

Received: 19 December 2013 Accepted: 18 February 2014 Published: 24 February 2014

\section{References}

1. Oberdörster G, Stone V, Donaldson K: Toxicology of nanoparticles: A historical perspective. Nanotoxicology 2007, 1:2-25.

2. Sinha R, Khare SK: Molecular basis of nanotoxicity and interaction of microbial cells with nanoparticles. Curr Biotechnol 2013, 2:64-72.

3. Ray PC, Yu H, Fu PP: Toxicity and environmental risks of nanomaterials: challenges and future needs. J Environ Sci Health C 2009, 27:1-35.

4. Lynch I, Dawson KA: Protein-nanoparticle interactions. Nano Today 2008, 3:40-47.

5. Mahmoudi M, Lynch I, Ejtehadi MR, Monopoli MP, Bombelli FB, Laurent S: Protein-nanoparticle interactions: opportunities and challenges. Chem Rev 2011, 111:5610-5637.

6. Sinha R, Karan R, Sinha A, Khare SK: Interaction and nanotoxic effect of $\mathrm{ZnO}$ and $\mathrm{Ag}$ nanoparticles on non-halophilic and halophilic bacterial cells. Bioresour Technol 2011, 102:1516-1520.

7. Karan R, Kumar S, Sinha R, Khare SK: Halophilic microorganisms as source of novel enzymes. In Microorganisms in Sustainable Agriculture and Biotechnology. Edited by Satyanarayana T, Johri BN. Netherlands: Springer; 2012:555-579.

8. Dodia MS, Bhimani HG, Rawal CM, Joshi RH, Singh SP: Salt dependent resistance against chemical denaturation of alkaline protease from a newly isolated Haloalkaliphilic Bacillus sp. Bioresour Technol 2008, 99:6223-6227.

9. Karan R, Khare SK: Stability of haloalkaliphilic Geomicrobium sp. protease modulated by salt. Biochemistry (Mosc) 2011, 76:686-693.

10. Nie S, Xing Y, Kim GJ, Simons JW: Nanotechnology applications in cancer. Annu Rev Biomed Eng 2007, 9:257-288.

11. Marcato PD, Duran N: New aspects of nanopharmaceutical delivery systems. J Nanosci Nanotechnol 2008, 8:2216-2229.

12. McBain SC, Yiu HH, Dobson J: Magnetic nanoparticles for gene and drug delivery. Int J Nanomed 2008, 3:169-180.

13. Colmenares JC, Luque R: Heterogeneous photocatalytic nanomaterials: prospects and challenges in selective transformations of biomassderived compounds. Chem Soc Rev 2014. 10.1039/C3CS60262A.

14. Shrivastava S, Bera T, Roy A, Singh G, Ramachandrarao P, Dash D: Characterization of enhanced antibacterial effects of novel silver nanoparticles. Nanotechnology 2007, 18:225103.

15. Zhang $\mathrm{H}$, Xiong $\mathrm{H}$ : Biological applications of $\mathrm{ZnO}$ nanoparticles. Mol Imaging 2013, 2:177-192

16. Smith EL, Markland FS, Kasper CB, DeLange RJ, Landon M, Evans WH: The complete amino acid sequence of two types of Subtilisin, BPN' and Carlsberg. J Biol Chem 1966, 241:5974-5976.

17. Kulakova L, Galkin A, Kurihara T, Yoshimura T, Esaki N: Cold-active serine alkaline protease from the psychrotrophic bacterium Shewanella strain ac10: gene cloning and enzyme purification and characterization. Appl Environ Microbiol 1999, 65:611-617. 
18. Karan R, Singh RK, Kapoor S, Khare SK: Gene identification and molecular characterization of solvent stable protease from a moderately haloalkaliphilic bacterium, Geomicrobium sp. EMB2. J Microbiol Biotechnol 2011, 21:129-135.

19. Deole R, Challacombe J, Raiford DW, Hoff WD: An extremely halophilic proteobacterium combines a highly acidic proteome with a low cytoplasmic potassium content. J Biol Chem 2013, 288:581-588.

20. Bardavid RE, Oren A: Acid-shifted isoelectric point profiles of the proteins in a hypersaline microbial mat: an adaptation to life at high salt concentrations? Extremophiles 2012, 16:787-792.

21. Chen K, Xu Y, Rana S, Miranda OR, Dubin PL, Rotello VM, Sun L, Guo X: Electrostatic selectivity in protein-nanoparticle interactions. Biomacromolecules 2011, 12:2552-2561.

22. Chakraborti S, Chatterjee T, Joshi P, Poddar A, Bhattacharyya B, Singh SP, Gupta V, Chakrabarti P: Structure and activity of lysozyme on binding to ZnO nanoparticles. Langmuir 2012, 26:3506-3513.

23. Chatterjee T, Chakraborti S, Joshi P, Singh SP, Gupta V, Chakrabarti P: The effect of zinc oxide nanoparticles on the structure of the periplasmic domain of the Vibrio cholerae ToxR protein. FEBS J 2010, 277:4184-4194.

24. Khan MJ, Qayyum S, Alam F, Husain Q: Effect of tin oxide nanoparticle binding on the structure and activity of a-amylase from Bacillus amyloliquefaciens. Nanotechnology 2011, 22:455708.

25. Xu Z, Liu XW, Ma YS, Gao HW: Interaction of nano- $-\mathrm{TiO}_{2}$ with lysozyme: insights into the enzyme toxicity of nanosized particles. Environ Sci Pollut Res Int 2010, 17:798-806.

26. Qiu H, Lu L, Huang X, Zhang Z, Qu Y: Immobilization of horseradish peroxidase on nanoporous copper and its potential applications. Bioresour Technol 2010, 101:9415-9420.

27. Sinha R, Khare SK: Characterization of detergent compatible protease of a halophilic Bacillus sp. EMB9: Differential role of metal ions in stability and activity. Bioresour Technol 2013, 145:357-361.

28. Karan R, Khare SK: Purification and characterization of a solvent-stable protease from Geomicrobium sp. EMB2. Environ Technol 2010, 31:1061-1072.

29. Shimogaki H, Takeuchi K, Nishino T, Ohdera M, Kudo T, Ohba K, Iwama M, Irie M: Purification and properties of a novel surface active agent and alkaline-resistant protease from Bacillus sp. Agric Biol Chem 1991 $55: 2251-2258$

30. Bradford MM: A rapid and sensitive method for the quantitation of microgram quantities of protein utilizing the principle of protein-dye binding. Anal Biochem 1976, 72:248-254.

31. Perez-Iratxeta C, Andrade-Navarro MA: K2D2: Estimate of protein secondary structure from circular dichroism spectra. BMC Struct Biol 2007, 8:25-32.

doi:10.1186/2043-7129-2-4

Cite this article as: Sinha and Khare: Differential interactions of halophilic and non-halophilic proteases with nanoparticles. Sustainable Chemical Processes 2014 2:4.

Publish with ChemistryCentral and every
scientist can read your work free of charge
"Open access provides opportunities to our
colleagues in other parts of the globe, by allowing
anyone to view the content free of charge."
W. Jeffery Hurst, The Hershey Company.
- available free of charge to the entire scientific community
- peer reviewed and published immediately upon acceptance
- cited in PubMed and archived on PubMed Central
- yours - you keep the copyright
Submit your manuscript here:
http://www.chemistrycentral.com/manuscript/

